\title{
Finite Element Study on Continuous Rotating versus Reciprocating Nickel-Titanium Instruments
}

\author{
Mohamed I. El-Anwar ${ }^{1}$, Salah A. Yousief², Engy M. Kataia ${ }^{3}$, Tarek M. Abd \\ El-Wahab ${ }^{4}$
}

\begin{abstract}
In the present study, GTX and ProTaper as continuous rotating endodontic files were numerically compared with WaveOne reciprocating file using finite element analysis, aiming at having a low cost, accurate/trustworthy comparison as well as finding out the effect of instrument design and manufacturing material on its lifespan. Two 3D finite element models were especially prepared for this comparison. Commercial engineering CAD/CAM package was used to model full detailed flute geometries of the instruments. Multi-linear materials were defined in analysis by using real strain-stress data of NiTi and M-Wire. Non-linear static analysis was performed to simulate the instrument inside root canal at a $45^{\circ}$ angle in the apical portion and subjected to $0.3 \mathrm{~N} . \mathrm{cm}$ torsion. The three simulations in this study showed that M-Wire is slightly more resistant to failure than conventional NiTi. On the other hand, both materials are fairly similar in case of severe locking conditions. For the same instrument geometry, M-Wire instruments may have longer lifespan than the conventional NiTi ones. In case of severe locking conditions both materials will fail similarly. Larger cross sectional area (function of instrument taper) resisted better to failure than the smaller ones, while the cross sectional shape and its cutting angles could affect instrument cutting efficiency.
\end{abstract}

\section{Introduction}

As the stiffness of traditional stainless steel endodontic instruments increases with instrument size, it may be responsible for curvature defects such as apical transportation, ledging or zipping (1). Nickel titanium (NiTi) is the favorite material for manufacturing continuous rotating and reciprocating instruments as it is more flexible than stainless steel instruments, due to two unique properties: shape memory and super-elasticity (2). NiTi alloys contain approximately 56\% nickel and 44\% titanium (3), and have three microstructural phases; austenite, martensite and R-phase, which determine the metal mechanical properties in use $(3,4)$. The austenite phase (ductile) occurs at higher temperatures and lower stresses; the martensite phase (hard) occurs at lower temperatures and higher stresses, whereas R-phase is an intermediate phase forming in the forward and reverse transformation between austenite and martensite (4). The first commercially available NiTi rotary files were launched on the market by the mid-1990s. During the last two decades, increasing failure of continuous rotating $\mathrm{NiTi}$ instruments was intensively shot. Hence, improvements in alloy properties, manufacturing processes and new motions have been developed. In 2007, a new NiTi alloy termed M-Wire (Dentsply Tulsa-Dental Specialties, Tulsa, OK, USA) was developed by means of a proprietary thermomechanical processing procedure. Manufacturer's

\author{
'Department of Mechanical \\ Engineering, National Research \\ Centre, Giza, Egypt \\ ${ }^{2}$ Department of Restorative \\ Dentistry, Al-Farabi Dental College, \\ Jeddah, KSA and Faculty of Oral \\ and Dental Medicine, Department \\ of Crown \& Bridge, Al Azhar \\ University, Assiut, Egypt \\ ${ }^{3}$ Department of Restorative \\ and Dental Materials, National \\ Research Centre, Giza, Egypt \\ ${ }^{4}$ Department of Endodontics, \\ Faculty of Dentistry, Mansoura \\ university, Mansoura, Egypt
}

Correspondence: Mohamed 1. El-Anwar, National Research Centre, Egypt, 33 El Bohouth St., Dokki, Giza, P.0. 12622, Egypt. Tel: +2 01222431297. e-mail: anwar_eg@yahoo.com

Key Words: finite element analysis, endodontics, nickel titanium, M-Wire. data for M-Wire indicated significantly improved fatigue resistance in comparison with conventional NiTi alloys. Currently, M-wire is used for the manufacture of GT series $X$ instruments (Dentsply Tulsa-Dental Specialties), Wave One (Dentsply Maillefer, Ballaigues, Switzerland), Reciproc (VDW, Munich, Germany) and Protaper Next (Dentsply Tulsa-Dental Specialties).

Comparing both motions, rotary and reciprocation, the reciprocating system showed reduced torsional stress (extended fatigue life) (5). This is due to the smaller angular movement inducing less stress on the file in case of locking (6). Both continuous rotation and reciprocating instruments have the same probability to fail in case of locking, thus manufacturers recommend using one file per tooth. In this way, reciprocating instruments have been recommended by some authors to less experienced dentists (2).

Different parameters like cross-sectional designs, tapers and diameters contribute to NiTi instrument's failure resistance. Instruments with larger tapers ensure stronger resistance to torsional failure that helps maintain the cutting edge strength and cutting efficacy. It also results in higher bending stresses and lower resistance to flexural fatigue failure. Comparing three types of nickel-titanium rotary files (K3, ProFile and $\mathrm{RaCe}$ ) indicated that instrument taper of 0.06 showed less resistance to fracture than 0.04 taper instruments (7).

Comparing ProTaper and Mtwo for cyclic fatigue 
resistance indicated that the bigger the cross sectional area at the point of maximum stress the lower the lifespan of NiTi rotary instruments during a cyclic fatigue test (8). Increase in the flute length adds slenderness to the file body, resulting in decreased resistance to deformation (9). Cross section may also be an important factor regarding the fracture incidence. When comparing numerically triangular ProTaper files to U-fluted ProFile instruments by finite element analysis, stresses were lower and more evenly distributed in ProTaper instruments (10).

High cost and time consuming experimental studies (11-14) were implemented on different dental instruments according to ISO 3630-1 standard specification in order to statistically prove that heat treated instruments have better cutting efficiency and higher fatigue resistance than conventional NiTi files.

In this research, finite element analysis (FEA) was used to compare GTX and ProTaper continuous rotating endodontic files with WaveOne reciprocating files from the perspective of design and manufacturing material.

\section{Material and Methods}

Although three files were compared in this study, two finite element models were prepared. The first model was prepared for the WaveOne (Dentsply Maillefer, Ballaigues, Switzerland) small file - tip diameter $0.21 \mathrm{~mm}$ with taper $0.06 \mathrm{~mm} / \mathrm{mm}$-, which is equivalent to ProTaper (Dentsply Maillefer) F1 file -tip diameter $0.2 \mathrm{~mm}$ with taper $0.07 \mathrm{~mm} /$ $\mathrm{mm}$ in the apical part and decrease coronally. The file tip size was ISO-25 with an 8\% apical taper that decreased towards the coronal end. The manufacturing material was the only difference, M-Wire and NiTi for WaveOne and ProTaper files respectively, where minor differences in taper were neglected. In order to investigate the design effect, the second model was prepared for GTX (Dentsply Tulsa Dental Specialties, Tulsa, OK, USA) - tip diameter 0.2 $\mathrm{mm}$ with taper $0.06 \mathrm{~mm} / \mathrm{mm}$ - and WaveOne, both made from M-Wire but with different cross-sectional design.

The 3D geometric models were prepared on commercial engineering general purpose CAD/CAM software "Solid Works 2013" (Dassault Systèmes SolidWorks Corporation, Waltham, MA, USA). The geometric model was transferred as IGES file (15) to the meshing and finite element analysis package "ANSYS" version 14.5 (ANSYS Inc., Canonsburg, PA, USA). The meshing element was 20 nodes "Solid 186" which has three degrees of freedom (translations in the global directions). Mesh density is a parameter that improves the result accuracy and reduces artificial peak stresses by improving the representation of the actual geometry. The mesh density effect was evaluated before extracting results, so that the final simulations were carried out with 16,008 nodes and 15,976 elements for the first model and 11,707 nodes and 13,409 elements for the second one.

Conventional NiTi alloy and M-Wire alloy were used/ tested in this study, where multi-linear materials were defined as presented in Figure 1. Stepped real stress strain curves were fed into the finite element package. The transformation starting stress $\square_{s}$ and the transformation finishing stress $\square_{\mathrm{f}}$ are the stress values when, at the working temperature, the transformation between austenite and single variant martensite starts and finishes, respectively. The limit transformation strain $\square_{\mathrm{L}}$ is the amplitude of the transformation strain interval. The capacity to recover all the deformation (i.e. pseudo-elastic behavior) ends when the martensitic yielding stress ' $\square y$ ' and the martensitic yielding strain ' $\square_{y}$ ' (indicated as pseudo-elastic limits) are assessed (16).

Boundary conditions and loading were imposed to simulate the behavior of each file as bending and torsional conditions in compliance with the ISO 3630-1 specification. To test the bending resistance, the bending moment was calculated while the file was clamped $3 \mathrm{~mm}$ from the tip and the shaft was deflected until $45^{\circ}$ inclination (18). To evaluate the torsional resistance, the file was held at 3 $\mathrm{mm}$ from the tip and a clockwise torsional moment of 0.3 N.cm was applied.

Server HP ProLaint ML150, with Intel Xeon $3.2 \mathrm{GHz}, 10$ GB RAM, was used for solid modeling and finite element non-linear static analysis where each run took about $4 \mathrm{~h}$.

Following the same steps of previous analyses $(2,16,19)$ for instrument failure, in this research, non-linear static analysis under the worst loading conditions was performed. This analysis was followed by fatigue failure check on NiTi and M-Wire, stress vs number-of-cycles curves of both materials to estimate the instrument lifespan, as evaluation procedure steps in a previous study by Cheung et al. (19), using Bannantine et al. (20) equations;

$$
\begin{aligned}
\sigma_{a} & =k^{\prime}\left(\varepsilon_{a p}\right)^{n^{\prime}} \ldots \ldots(1)(20) \\
\varepsilon_{a} & =\frac{\sigma_{f}^{\prime}}{E}\left(2 N_{f}\right)^{b}+\varepsilon_{f}^{\prime}\left(2 N_{f}\right)^{c} \ldots \ldots
\end{aligned}
$$

Where $E$ is the modulus of elasticity, $\square_{\text {ap }}$ is plastic strain amplitude, $\square_{\mathrm{a}}$ and $\square_{\mathrm{a}}$ are total strain and total stress amplitudes respectively. NiTi parameters were used in evaluating fatigue behavior for both materials as listed in Table 1.

\section{Results}

Three simulations (runs) were performed in this research; the first two runs utilize the first model for WaveOne/ ProTaper file where the instrument materials were M-Wire and NiTi respectively. The third run was using GTX file model with M-Wire as a material; the three runs were operated 
under the same loading and boundary conditions.

The results showed that $\mathrm{M}$-Wire is slightly more resistant to failure than conventional NiTi. As presented in Figure 2 , total plastic strain represents the major part of the total equivalent strain in WaveOne instrument. On the other hand, the total elastic strain has a negligible effect, as illustrated in Figure 3. Comparing Figures 2A and 3A,

Table 1. Parameters used to evaluate fatigue behavior of Nickeltitanium (NiTi) wires (19)

\begin{tabular}{lcc}
\hline Parameter & Symbol & NiTi alloy \\
\hline Cyclic strain hardening exponent & $\mathrm{n}^{\prime}$ & 0.1 \\
Cyclic strength coefficient & $\mathrm{K}^{\prime}$ & $733 \mathrm{MPa}$ \\
Fatigue strength exponent & $\mathrm{b}$ & -0.06 \\
Fatigue strength coefficient & $\sigma_{\mathrm{f}}^{\prime}$ & $705 \mathrm{MPa}$ \\
Fatigue ductility exponent & $\mathrm{C}$ & -0.6 \\
Fatigue ductility coefficient & $\varepsilon_{\mathrm{f}}^{\prime}$ & 0.68 \\
\hline
\end{tabular}

ProTaper instrument showed less total equivalent strain and higher equivalent stress than WaveOne under the worst loading condition (locking condition), which indicate shorter lifespan for ProTaper in comparison to WaveOne. As the analysis was conducted on the same model, any lifespan extent with WaveOne is directly related to its manufacturing material (M-Wire).

On the other hand, in case of several locking conditions, both tested materials will fail after same number of locking cases due to their too close characteristics to each other (Fig. 1) and the possibility of failure under continuous rotation is too high in comparison with reciprocating motion.

GTX performance in comparison to WaveOne showed higher stress at lower strains. Figure 4A illustrates the stress state showing the stress concentration around the fixation level ( $3 \mathrm{~mm}$ from tip). In Figures $2 B$ and $4 B$, the equivalent plastic strain distribution indicated squeezing of GTX at fixation level (plan). As the M-Wire is the manufacturing material for both instruments, the instrument and its cross section design is the only reason for the stress value
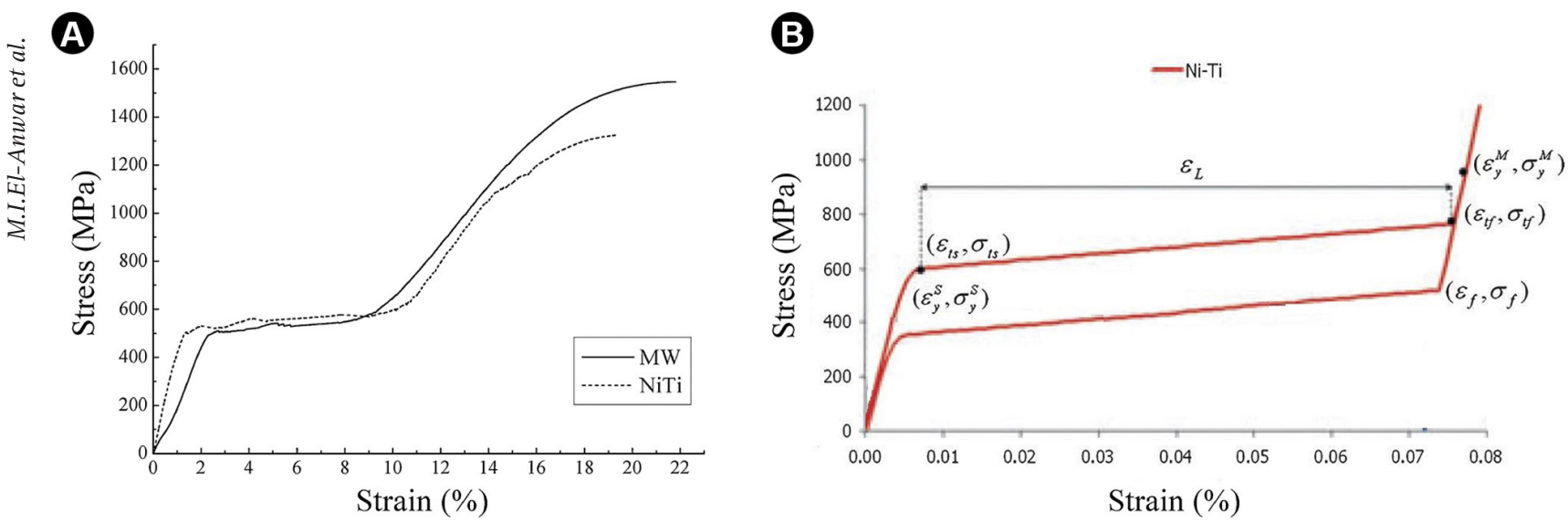

Figure 1. Conventional NiTi alloy and M-Wire alloy stress strain curves (17), and simplified multi-liner conventional NiTi material used in analysis.

(4)

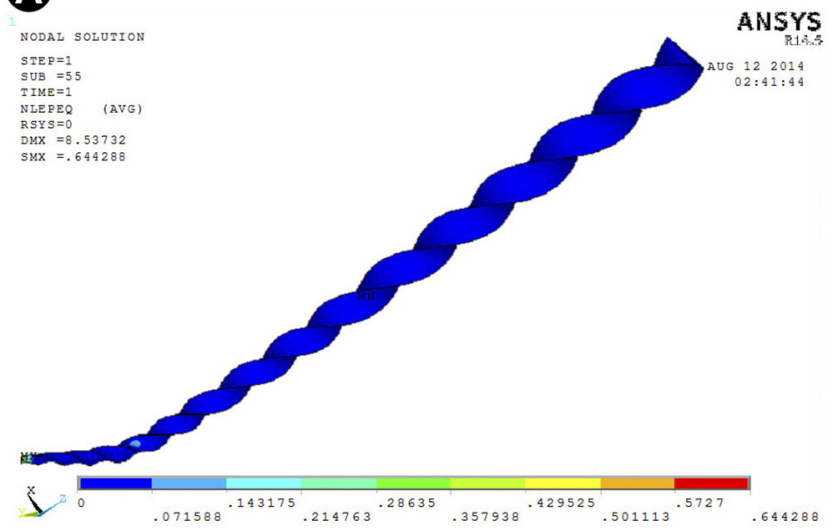

B

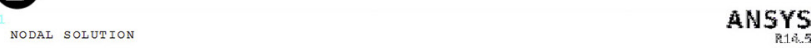

$S T E P=1$
$S M B=55$

STER $=1$
SUME $=5$
TIME $=1$

EPTOE QV (AVG)
DMX $=8.53735$

DMX $=8.53732$
SMN $=.407 \mathrm{E}-03$
$\operatorname{SMY}=.660104$

AUG $12: 2014$
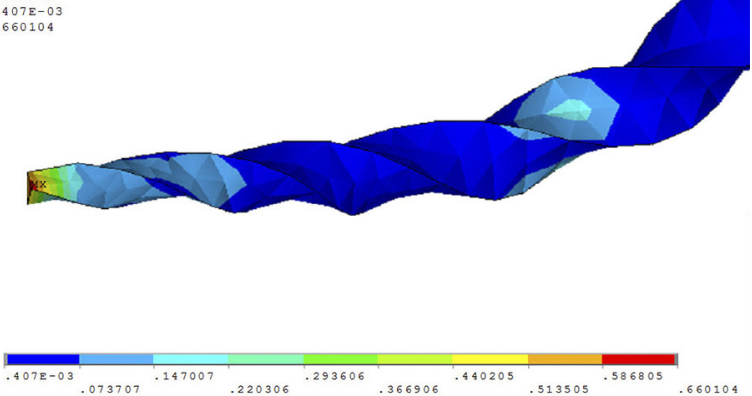

Figure 2. WaveOne file total strain equivalent (A) and plastic (B). 
variations. This indicated longer lifespan of WaveOne instruments for the same operating conditions.

\section{Discussion}

Finite element results or any other numerical analysis may differ from the clinical use, as some variables were not taken into consideration, such as friction with dentine walls, complex root canals, eventual gradients of temperature. But the applied loads and boundary conditions for both models might give reliable indication about the expected clinical performance.

By mechanical principles, the reciprocating system has three advantages over the continuous rotating one. The first advantage is reduced torsional stress, since during reciprocating movement counterclockwise, the instrument engages dentin at its tip, and disengages immediately with the clockwise movement (21). Second, extended fatigue life of the NiTi file when used in reciprocation compared to continuous rotation, which may be explained by smaller angular movement that induces less stress on the file in case of locking (2). Finally, hammering action of the reciprocating motion of the file's cutting edge increase the applied load on the root canal to double its value.

File cross sectional area is the dominant parameter affecting the instrument lifespan, as the cross sectional shape and angles affect directly the cutting efficiency of instrument. That matching proved the hypothesis and findings in previous studies $(2,19)$, where NiTi instruments and wires showed similar behavior even with different cross section designs but equivalent cross section area. At $3 \mathrm{~mm}$ from file tip, GTX file cross sectional area is about $30 \%$ less than the WaveOne one. Therefore, by mechanical principles, large cross sectional areas resist failures better than the smaller ones. Cross sectional shape is responsible for maximum bending stress fluctuations at cross section circumference. The WaveOne cross sectional design allows

B

(A)

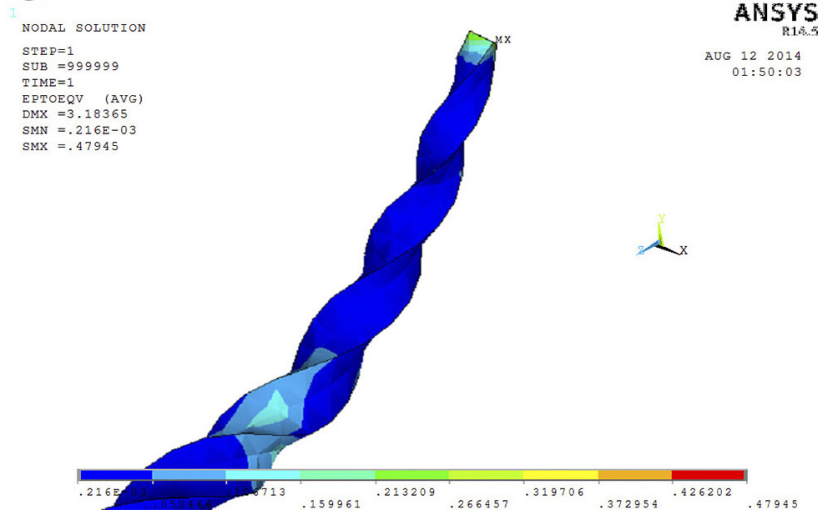

Figure 3. Protaper file total strain equivalent (A) and elastic (B).

\section{A}

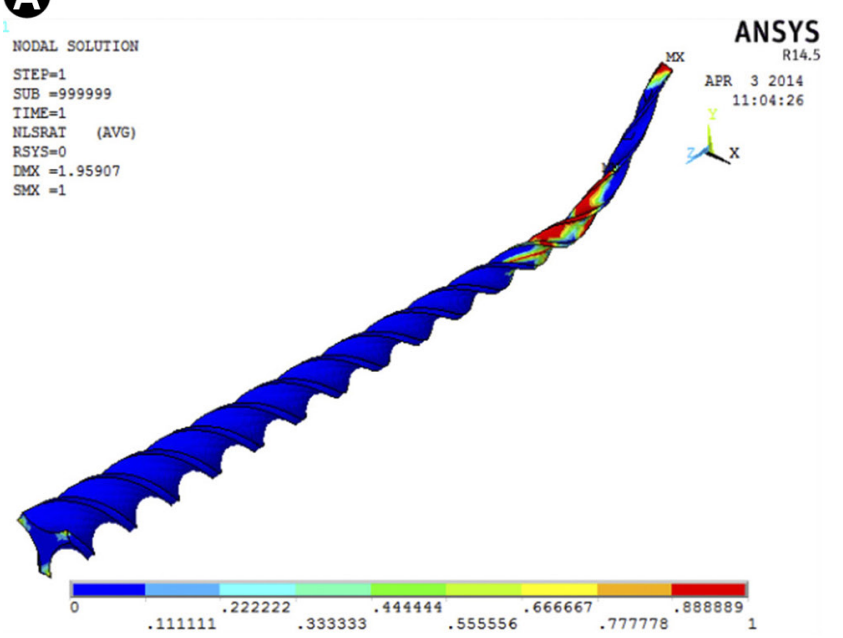

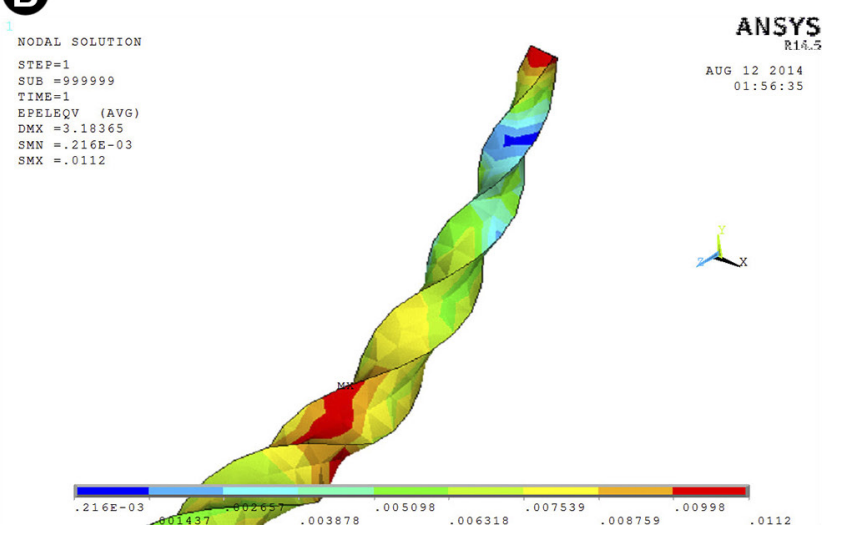

B

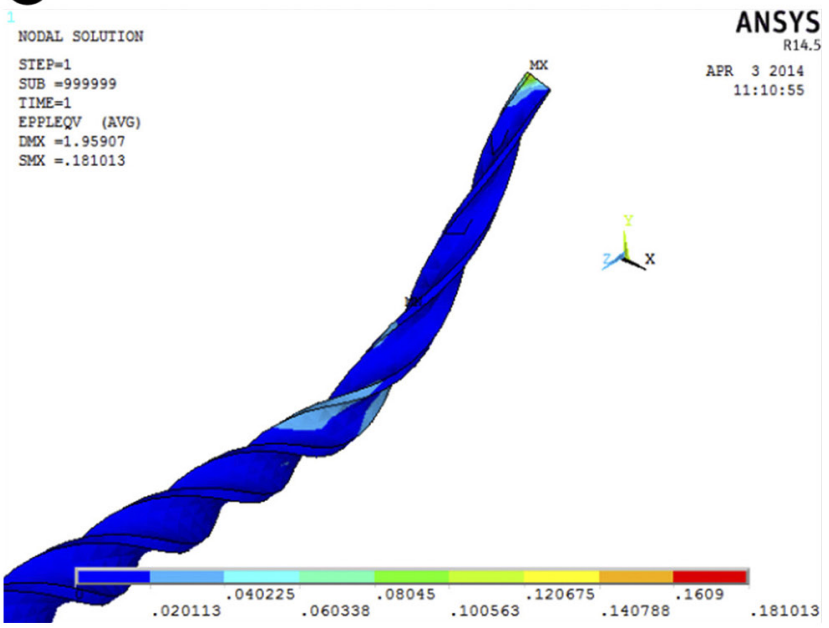

Figure 4. GTX file stress state (A) and total plastic strain (B). 
gradual changes in maximum bending stress, while the GTX cross sectional design is subjected to sudden changes that result in peaks or high fluctuations at maximum bending stress. In addition, cross section design defines the cutting edges and its supporting material, since the supporting material increases the expected file lifespan. This point was clearly observed by WaveOne's longer lifespan in comparison to GTX results in different studies $(13,14)$. Finally, cutting angles defined by the file cross-section design strongly affect the instrument's cutting efficiency.

Logically, the stiffness and flexibility of a file depend greatly on its geometric design, including taper, helix angle, cross section, tip size and length. The taper feature adds more material to the file and makes a stiffer body, which affects both bending and torsional behavior of the file. A larger taper offers stronger resistance to torsional breaks and helps maintain the cutting edge strength and cutting efficacy. It also results in higher bending stresses and lower resistance to flexural fatigue failure. Therefore, a large tapered file is appropriate when increased stiffness or high cutting efficacy is required, like during the initial orifice enlargement or while preparing the coronal half. In contrast, a file with small taper is suitable for severely curved or S-shaped canals where great flexibility is needed (9).

The results obtained from FEA agree with previous studies by Montalvao et al. (22-24) when they compared mechanical properties of Profile GT (conventional NiTi) and GTX (M-Wire) using FEA and their results showed that GTX is more capable of stress relief than the GT file. Therefore, $\mathrm{M}$-Wire instruments displayed better wear resistance due to higher hardness compared to conventional NiTi instruments. The increased hardness of M-Wire instruments is attributed to the special work-hardened martensite structure found by scanning transmission electron microscopy (STEM), of starting wire blanks and metallographic examination of the etched microstructures of instruments (25). Mechanical properties of M-Wire instruments are improved (increased hardness) and may provide improved cutting efficiency. STEM analysis of M-Wire and conventional NiTi wire revealed that M-Wire has relatively coarse grains, numerous triple-point junctions of grain boundaries, and localized deformation bands with microtwins, indicating extensive thermomechanical processing (25). This efficient use of alloy strengthening mechanism accounts for the superior mechanical properties of M-Wire compared to conventional superelastic wire for rotary instruments (25).

WaveOne files used with reciprocation motion have more resistance to cyclic fatigue than continuous rotation ProTaper and GTX files.

M-Wire instruments may have longer lifespan than conventional NiTi, but in case of severe locking conditions both materials will fail similarly.
Larger cross sectional areas are better for failure resistance than the smaller ones, while cross sectional shape and cutting angles affect instrument cutting efficiency.

\section{Resumo}

As limas rotativas GTX e ProTaper foram comparadas numericamente com as limas reciprocatórias WaveOne pela análise de elementos finitos, com o objetivo de baixar custos, comparação fiel e exata, além de pesquisar o efeito do projeto das limas e de seu material sobre a durabilidade. Dois modelos tridimensionais de análise de elementos finitos foram especialmente elaborados para esta comparação. Utilizou-se um sistema de engenharia CAD/CAM comercial para construir o modelo totalmente detalhado da geometria das estrias das limas. Materiais multi-lineares foram definidos na análise usando dados reais de deformação por estresse de NiTi e M-Wire. Procedeu-se à análise estática não linear para simular a ação do instrumento dentro do canal radicular em ângulo de $45^{\circ}$ na região apical, submetido a uma torsão de $0.3 \mathrm{~N} . \mathrm{cm}$. As três simulações realizadas no presente estudo demonstraram que o M-Wire é um pouco mais resistente a falhas que o NiTi convencional. Por outro lado, ambos os materiais são bastante similares em condições de travamento severo. No caso da geometria das limas, os instrumentos de M-Wire podem ter vida útil mais longa que os de NiTi convencional. Em condições de travamento severo, ambos os materiais terão falhas similares. Maior área transversal (em função da conicidade do instrumento) resiste melhor a falhas que as áreas transversais menores, ao passo que a geometria da área transversal e seus ângulos de corte podem afetar a eficiência de corte das limas.

\section{References}

1. Schäfer E, Tepel J, Hoppe W. Properties of endodontic hand instruments used in rotary motion. Part 2. Instrumentation of curved canals. J Endod 1995;21:493-497.

2. El-Anwar MI, Mandorah A0, Yousief SA, Soliman TA, Abd El-Wahab TM. A finite element study on mechanical behavior of reciprocating dental files. Braz J Oral Sci 2015;14:52-59.

3. Shen Y, Zhou HM, Zheng YF, Peng B, Haapasalo M. Current challenges and concepts of the thermomechanical treatment of nickel-titanium instruments. J Endod 2013;39:163-172.

4. Thompson SA. An overview of nickel-titanium alloys used in dentistry. Int Endod J 2000;33:297-310.

5. Pirani C, Ruggeri 0, Cirulli PP, Pelliccioni GA, Gandolfi MG, Prati C. Metallurgical analysis and fatigue resistance of WaveOne and ProTaper nickel-titanium instruments. Odontology 2014;102:211-216.

6. Lopes HP, Vieira MVB, Elias CN, Siqueira Jr JF, Mangelli M, Lopes WSP, et al.. Fatigue life of WaveOne and ProTaper instruments operated in reciprocating or continuous rotation movements and subjected to dynamic and static tests. Endod Pract Today 2013;7:217-222.

7. Yao JH, Schwartz SA, Beeson TJ. Cyclic fatigue of three types of rotary nickel-titanium files in a dynamic model. J Endod 2006;32:55-57.

8. Grande NM, Plotino G, Pecci R, Bedini R, Malagnino VA, Somma F. Cyclic fatigue resistance and three-dimensional analysis of instruments from two nickel-titanium rotary systems. Int Endod J 2006;39:755-763.

9. He R, Ni J. Design improvement and failure reduction of endodontic files through finite element analysis: application to V-Taper file designs. J Endod 2010;36:1552-1557.

10. Berutti E, Chiandussi G, Gaviglio I, Ibba A. Comparative analysis of torsional and bending stresses in two mathematical models of nickel-titanium rotary instruments: ProTaper versus ProFile. J Endod 2003;29:15-19.

11. Plotino G, Rubini AG, Grande NM, Testarelli L, Gambarini G. Cutting efficiency of Reciproc and WaveOne reciprocating instruments. J Endod 2014;40:1228-1230.

12. Braga LC, Faria Silva AC, Buono VT, de Azevedo Bahia MG. Impact of heat treatments on the fatigue resistance of different rotary nickeltitanium instruments. J Endod 2014;40:1494-1497.

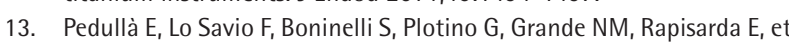
al.. Influence of cyclic torsional preloading on cyclic fatigue resistance 
of nickel-titanium instruments. Int Endod J 2014; doi: 10.1111/ iej.12400.

14. Abd El-Wahab TM. Thesis: Cyclic fatigue resistance and finite element analysis of continuous versus reciprocating motion of three different rotary nickel-titanium instruments. Mansoura University, 2015.

15. El-Anwar MI. Simple technique to build complex 3D solid models. Proceedings of 19th International Conference on Computer Theory and Applications (ICCTA 2009). 17- 19 0ct. 2009, Alexandria, Egypt.

16. Necchi S, Petrini L, Taschieri S, Migliavacca F. A comparative computational analysis of the mechanical behavior of two nickeltitanium rotary endodontic instruments. J Endod 2010;36:1380-1384.

17. Pereira ES, Gomes RO, Leroy AM, Singh R, Peters OA, Bahia MG, et al.. Mechanical behavior of M-Wire and conventional NiTi wire used to manufacture rotary endodontic instruments. Dent Mater 2013;29:e318-e324.

18. Santos LA, Bahia MG, Casas EB, Buono VT. Comparison of the mechanical behavior between controlled memory and superelastic nickel-titanium files via finite element analysis. J Endod 2013;39:14441447.

19. Cheung GS, Zhang EW, Zheng YF. A numerical method for predicting the bending fatigue life of $\mathrm{NiTi}$ and stainless steel root canal instruments. Int Endod J 2011;44:357-361.

20. Bannantine JA, Comer JJ, Handrock JL. Fundamentals of Metal Fatigue Analysis. Upper Saddle River: Prentice Hall; 1989. p.38.
21. Pirani C, Ruggeri O, Cirulli PP, Pelliccioni GA, Gandolfi MG, Prati C. Metallurgical analysis and fatigue resistance of WaveOne and ProTaper nickel-titanium instruments. Odontology 2014;102:211-216.

22. Montalvao D, Alcada FS. Numeric comparison of the static mechanical behavior between ProFile GT and ProFile GT series X rotary nickeltitanium files. J Endod 2011;37:1158-1161.

23. Montalvao D, Alcada FS, Braz Fernandes FM, de Vilaverde-Correia S. Structural characterization and mechanical FE analysis of conventional and $\mathrm{M}$-Wire $\mathrm{Ni}-\mathrm{Ti}$ alloys used in endodontic rotary instruments. Sci World J 2014: ID 976459.

24. Montalvao D, Shengwen Q, Freitas M. A study on the influence of Ni-Ti $\mathrm{M}$-Wire in the flexural fatigue life of endodontic rotary files by using finite element analysis. Mater Sci Eng C Mater Biol Appl 2014;40:172179.

25. Jie Liu. Thesis: Characterization of new rotary endodontic instruments fabricated from special thermo-mechanically processed NiTi wire. Ohio State University, 2009.

Received August 20, 2015 Accepted May 17, 2016 